\title{
Key Lessons Learnt from Stakeholder Management in Design and Build Projects in Qatar
}

\author{
Larno Meyer \\ lmeyer@ashghal.gov.qa \\ Highway Projects Department, Public Works Authority, Doha, Qatar \\ Ali Kara \\ akara@ashghal.gov.qa \\ Highway Projects Department, Public Works Authority, Doha, Qatar
}

\begin{abstract}
Stakeholders in the construction industry require accurate, reliable and timely information in order to streamline the design and construction of Projects. Design Bid Build or Design and Build contracts need a process for seeking the latest requirements, interests and existing assets of all the stakeholders involved. This to lead and guide the projects to deliver in a timely, cost-effective and safe manner. This paper summarizes the multi-discipline Stakeholder management challenges and their proactive approach during the execution of the Expressway Programme by Public Works Authority, Qatar illustrated by a case study and actual actions from the industry. Various internal surveys have been undertaken to assess the issues to be resolved. Key to managing the time and cost impacts on the construction projects are identifying the needs of stakeholders, stakeholder communication procedures, their requirements, identification of existing assets, expected future requirements and decisions among the stakeholder. Unique and innovation construction procedures are highlighted in order to overcome construction challenges.
\end{abstract}

Keywords: Stakeholders management; Stakeholder communication; Qatar expressway programme

\section{INTRODUCTION}

Qatar Public Works Authority's (Ashghal) Highway Projects Department set out to deliver over 45 major Expressway Road Projects to be completed before the FIFA World Cup in 2022. These projects accounts for over $800 \mathrm{~km}$ of new major road network improvements (together with the road improvement works also for the local road projects). These projects were needed to help resolve the traffic congestion due to the increase in population and economic growth of Qatar.

To be able to deliver this large number of major projects in the Expressway Programme within Ashghal various stakeholders had to be consulted to understand their requirements and inputs to each project and to obtain their approvals to proceed into construction. These stakeholders involve both the internal and external groups of people from various departments, ministries, utility authorities and private entities. 


\section{UNDERSTANDING THE MULTI-DISCIPLINE STAKEHOLDER APPROVAL CHALLENGES}

Due to the large number of major projects and stakeholders that must be managed simultaneously, it led to various multi-discipline stakeholder approval challenges across the projects' design and construction interfaces. This formed part of the initial key lessons learnt. The Project Teams should fully understand how the multi-discipline engineering interfaces influence each other during the design development. Each project has Traffic, Roads, Utility and Structure Engineering Teams working along with their Project Management and Project Controls Teams. Projects all have multiple interfaces that need to collaborate effectively during design and construction.

These multi-discipline interfaces include for example, the work on the initial traffic analysis needed to produce concept designs, the road geometry, all the different utility corridors (both new and existing), multiple large structures (bridges and tunnels), limiting land acquisition and environmental impacts, improving road safety, integration with public transport modes, ensuring proper risk management and controlling the overall cost and schedule. Various engineering disciplines therefore needed to work together to complete projects on time and on budget. Each of these engineering disciplines required various stakeholder approvals. It was therefore necessary to identify all the stakeholders for each discipline's approval as early as possible in the Expressway Programme.

\section{THE IMPORTANCE OF STAKEHOLDER IDENTIFICATION AND ANALYSIS}

Stakeholders are those groups or individuals that can influence and impact a project. On the other hand, they can be affected by a project. Stakeholders can have a positive or negative influence on a project [PMI]. It is therefore important to identify all stakeholders for each project as early as possible and to start engaging with each stakeholder.

Another key lesson was to understand the full scope and scale of all stakeholders involved with Ashghal's projects. For each of Ashghal's projects there can be more 10 internal stakeholders (Departments and Sections) and more than 30 external stakeholders (Ministries, Utility Authorities, Private Entities and their different internal departments). It requires full collaboration with each stakeholder during the duration of the projects from design stage to construction.

After identifying the specific stakeholders, Stakeholder Analysis (Schmeer, 1999) is also required to identify the different types of stakeholders involved and how each stakeholder may influence or impact a project. Some stakeholders have higher levels of power and influence which can approve or oppose decisions on a project. Other stakeholders can help provide expert opinions, inputs and support even if they do not have direct interest in a project's delivery. There are also stakeholders that need to know the progress of work as it can influence their own activities and work to be completed. It is therefore necessary to make use of stakeholder analysis techniques to help understand how to engage and communicate to each stakeholder.

\subsection{Stakeholder Analysis Techniques}

There are several Stakeholder Analysis Techniques that can be used to understand the interest and influence of each Stakeholder and how to manage each of these stakeholders. 
These analysis techniques are also visual mapping tools to help guide the Project Teams on who to focus on as key stakeholders. The Stakeholder Analysis Techniques can include for example:

- 2x2 Grid Analysis (Power / Influence vs. Interest or Influence vs. Impact, Figure 1, (Mendelow, 1981).

- Salience stakeholder analysis (Venn Diagram) (Mitchell, Agle, B. \& Wood, D., 1997).

- Stakeholder Circles to reflect the influence of stakeholders on a project (Bourne, Walker, DHT, 2005).

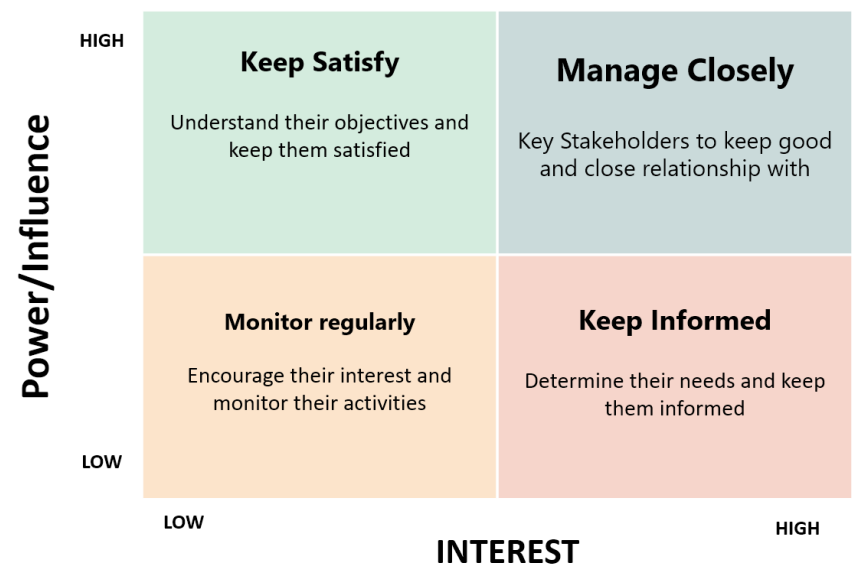

Figure 1: 2x2 Analysis Grid (Power/Influence vs. Interest) (Mendelow, 1981)

\section{STAKEHOLDER ENGAGEMENT AND COMMUNICATION MANAGEMENT}

\subsection{Stakeholder Communication Plans and Procedures}

As part of the PMI Project Management Process Groups and Knowledge Area, is the important requirement of Stakeholder Management and Engagement (PMI, Chapter-1, 2017). This also includes Planning the Communication Management (PMI, Chapter-10, 2017) and the specific procedures to follow for each stakeholder identified. The following questions can be asked to obtain an initial understanding of what should be considered in the Stakeholder Engagement and Communication Planning:

- Who are the key stakeholder decision makers to engage and communicate to for approvals?

- What are these stakeholders' requirements and procedures to follow to obtain their inputs and approvals?

- How often to report and follow up with each stakeholder (weekly, bi-weekly or monthly)?

\subsection{Implementing Memorandums of Understanding (MoUs)}

Various Memorandums of Understanding (MoUs) were implemented between 
Ashghal and external authorities to improve the approval processes. These MoUs sets out the agreed principles, accepted expectations and requirements that Ashghal and each Authority will follow. It helped to ensure better collaboration and understanding between all involved using a less formal contractual agreement process. It also helped to define the needs and actions for each stakeholder. These MoUs have been setup following various workshops and discussion. This to obtain the inputs needed to formulate each Memorandum of Understanding.

\section{UNDERSTANDING THE COMPLEXITY IN STAKEHOLDER COMMUNICATION}

Complexity in project communication results when there are multi-discipline interfaces across multiple stakeholders simultaneously. This while also dealing with changing deliverables to be delivered with available resources. As projects are fast moving and requirement changes are many times undefined, ambiguity and miscommunication or misinterpretation can also result. This increases the complexity of delivering projects in time and on budget.

\subsection{Equation to calculate the number of communication channels between stakeholders}

In Project Management there is an equation (PMI, Chapter-10, 2013) that defines the number of communication channels (links) between all individuals or groups of people. This equation can help to indicate the complexity of a project, as it reflects on the number of communication channels involved. As the number of communication channels increase, the more complex a project will become. This includes stakeholder communication. Also, more communication channels can result in miscommunication or misinterpretation which can cause delays in project approvals. The following is the equation that can show the number of Communication Channels involved.

$$
\begin{aligned}
& \text { Number of Communication Channels (links) }=N(N-1) / 2 \\
& \mathrm{~N}=\text { number of individuals or groups }
\end{aligned}
$$

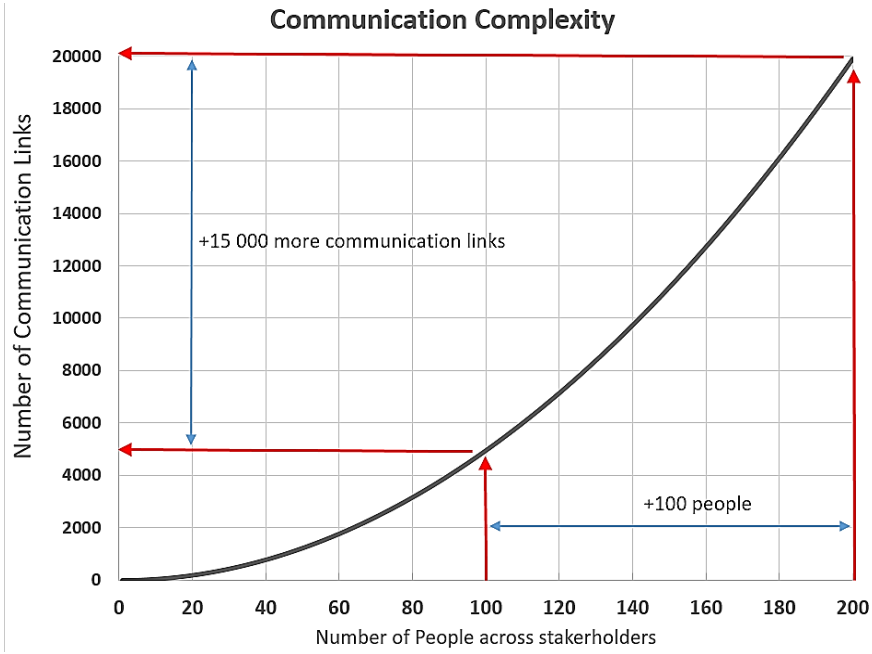

Figure 2: Graph showing the Number of communication channels between stakeholders 
The graph in Figure 2, shows that if 100 people are involved across the various stakeholders, then there will be close to 5000 communication channels (links) created between all the people. Should this number of people double, then the number of communication channels will increase from 5000 to 20000 (400\%). Therefore, it is important to understand that if more people are involved the complexity in communication will increase. This can contribute to delaying approval processes if not managed well.

\subsection{The importance of reducing the number of communication channels between multiple Stakeholders}

It is very important to identify the key communication contacts within each stakeholder. This to limit the number of people to communicated to. Channels of communication should be setup through each key communication contact in each stakeholder. This will reduce the number of direct communication links and simplify the complexity of communication across each project.

For example, instead of having to deal directly with more than 100 individual contacts across the different stakeholders, one should aim to focus only of the key decision makers who can report back to their teams. By reducing the number of people to communicate to, the complexity can be reduced. This is return can also help to reduce miscommunication and ambiguity or misunderstandings which can delay approvals.

\subsection{The importance of Cultural Awareness and Cross-Cultural Communication Styles}

Another key lesson learnt in working in a multi-cultural environment with people coming from across the world, is the complexity in how people communicate and relate to each other. The PMI PMBOK $6^{\text {th }}$ Edition (2017) provides a good summary and states the following: "Cultural awareness is an understanding of the differences between individuals, groups, and organizations and adapting the project's communication strategy in the context of these differences. This awareness and any consequent actions minimize misunderstandings and miscommunication that may result from cultural differences within the project's stakeholder community. Cultural awareness and cultural sensitivity help the project manager to plan communications based on the cultural differences and requirements of stakeholders and team members."

\section{INNOVATIVE DIGITAL SYSTEMS FOR STAKEHOLDER ENGAGEMENT AND COMMUNICATION DURING THE REVIEW AND APPROVAL PROCESSES}

\subsection{QDES / QDRS - Stakeholder review and approval system for design}

Ashghal's Online Qatar Design Enquiry System (QDES) or also refer to as Qatar Design Review System (QDRS) have been implemented to enhance stakeholder engagement and communication during the approval process. These systems helped to improve sharing information and speed up the coordination between stakeholders.

It provides more transparency of work activities done by various stakeholders across Qatar and helps to identify potential clashes and overlaps. It also provides a paperless web base submission platform that helped to reduce the overall time. The system provides 
a time line to follow, which helped to expedite the review process that took longer in the past. Should the time line not being followed, the application is automatically cancelled by system.

\subsection{QPro - Road Opening Permits, Approval to work in Right of Way (ROW)}

Similar to Ashghal's QDES/QDRS systems, the QPRO system has been created to process Road Opening and Occupancy permit approvals. This applies for all Stakeholders. It is a mandatory process and also applies to the construction phase.

If for example, a Utility Authority wants to implement a new pipe or cable within the Right of Way, they need to obtain from Ashghal a Road Opening Permit approval to do the work within Right of Way (ROW). This process helps to control the work done by the different stakeholders within their respective ROW corridors.

QPRO is dependent on QDES/QDRS system and forms part of the approval process. It is mandatory for all stakeholders to apply for a Road Opening Permit on the QPRO system by using a unique Design Review number for any work associated with excavation.

\subsection{IBM BlueWorks - Work flow and Process guidelines}

IBM's BlueWorks is a business process-modeling tool that is based on a Flow Chart driven web portal. This tool provides access to all Ashghal's processes and procedures with the related documentation and reference to the internal stakeholders (Departments, Sections) involved. It provides a quick visual step by step process of decision points and approvals needed with the related forms and documents involved.

\section{HIGHWAY PROJECT DEPARTMENT CASE STUDY AND LESSONS LEARNT}

The following is a case study for the Highway Project Department (HPD). The diagram below Figure 3 indicates the main internal and external stakeholder interfaces and interactions in relation to HPD. This reflects on all approval processed from Concept Design Stage to Preliminary and Detail Design approvals and then the Tendering and Construction Stages.

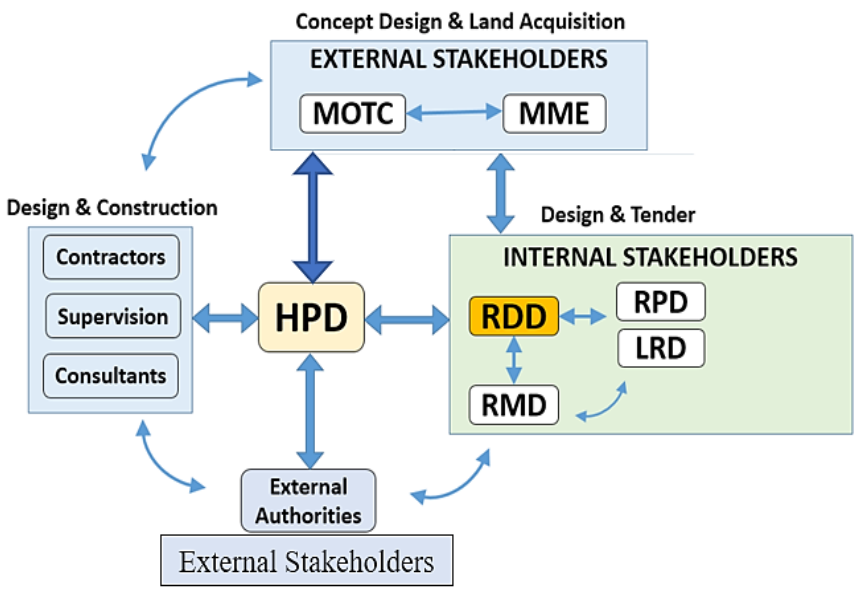

Figure 3: Highway Projects Department (HPD) Case Study 
Where:

MoTC - Ministry of Transportation \& Communication.

MME - Ministry of Municipalities \& Environment.

RDD - Road Design Department.

RPD - Road Projects Department (Local Roads).

LRD - Local Roads \& Drainage Department.

RMD - Road Maintenance Department.

External Stakeholders include for example: Kahramaa, MoI, PEO, QP, QRail \& Ooredoo.

During the duration of a HPD project, which involves all of these multiple interfaces and interactions with internal and external stakeholder, it became clear that the following issues had to be resolved as part of improving the stakeholder engagement and communication processes:

- Internal and External Stakeholder communication issues between departments/ Sections (misinterpretation / miscommunication issues).

- Missing, unclear or changing standards, requirements and guidelines not fully and officially communicated to all involved and in a timely matter.

An example of where good stakeholder coordination benefited the community and improved safety, is along the new Sabah Al Ahmad Road Corridor between Salwa and Al Waab Roads. To ensure the safety of schoolchildren during the ongoing construction and temporary traffic management, an additional school bus service has been added. This avoided children to cross the Construction Work Zone area and the temporary traffic road diversions.

Also for the Temporary Traffic Management, coordination with MoI Traffic Police made it possible to decide on the most effective way to accommodate the traffic flows during construction in a very restricted urban area.

Other example includes the Memorandum of Understanding (MoU) with Qatar Electricity and Water Co. MoU helped to improve the approval processes for water and electrical utility corridors and electrical substations. Ashghal HPD also holds regular high-level stakeholder coordination meetings where major issues on projects are discussed to obtain high-level approval.

\section{CONCLUSION}

From the above it is concluded that stakeholder management is vital to the success of any project and even more when there are multiple major projects placed in design and construction at the same time. A large number of people from a diverse background will be involved across both the internal and external stakeholders. Should a multi-discipline project team fail to understand the various interfaces involved across a project (which requires full collaboration with multiple stakeholders), then long costly delays may result.

Project Teams should identify all stakeholders and their influence and interest to a project. In addition, each stakeholder's most current requirements for approval should be checked as early as possible. The project teams should ensure proper stakeholder 
communication plans are setup. Moreover, the number of key stakeholder contacts should be limited to avoid introducing unnecessary communication complexity, which can lead to miscommunication and delays in approvals. In addition, the use of information technology and the development of it, help to improve better stakeholder engagement and communication. Successful stakeholder engagement and management will result in the safe, cost and time effective delivery of projects.

\section{REFERENCES}

Bourne, L. \& Walker, D. H. T. (2005) Visualizing and mapping stakeholder influence. Management Decision, 43(5), 649660.

IBM BlueWorks Business Process Modeling, https://www.ibm.com/products/blueworkslive.

Mitchell, R., Agle, B. \& Wood, D. (1997). Toward a Theory of Stakeholder Identification and Salience: Defining the principle of Who and What really counts. The Academy of Management Review, 22(4), pp. 853-886.

Mendelow, A. L. (1981). Environmental Scanning - The Impact of the Stakeholder Concept, ICIS 1981 Proceedings, Paper 20.

Project Management Institute, PMI (2013). A Guide to the Project Management Body of Knowledge (PMBOK Guide, $5^{\text {th }}$ Ed), Chapter 10, 10.1.2.1, Newtown Square, Pennsylvania, USA.

Project Management Institute, PMI (2017). A Guide to the Project Management Body of Knowledge (PMBOK Guide, $6^{\text {th }}$ Ed), Chapter 13, Newtown Square, Pennsylvania, USA.

Project Management Institute, PMI (2017). A Guide to the Project Management Body of Knowledge (PMBOK Guide, $6^{\text {th }}$ Ed), Chapter 10, Newtown Square, Pennsylvania, the USA.

Project Management Institute, PMI (2017). A Guide to the Project Management Body of Knowledge (PMBOK Guide, $6^{\text {th }}$ Ed), Chapter 10, 10.1.2.6 (Cultural Awareness), Newtown Square, Pennsylvania, USA.

Schmeer, K. (1999). Guidelines for conducting a stakeholder analysis. 